\title{
Growth, Development, and Quality of Life in Children with Congenital Heart Disease
}

\author{
Sri Maya ${ }^{1 *}$, Eka Gunawijaya ${ }^{2}$, N. P. Veny Kartika Yantie $^{2}$, I. G. A. Trisna Windiani ${ }^{2}$ \\ ${ }^{1}$ Department of Child Health, Sondosia General Hospital, Bima, West Nusa Tenggara, Indonesia; ${ }^{2}$ Department of Child Health, \\ Faculty of Medicine, Udayana University, Denpasar, Indonesia
}

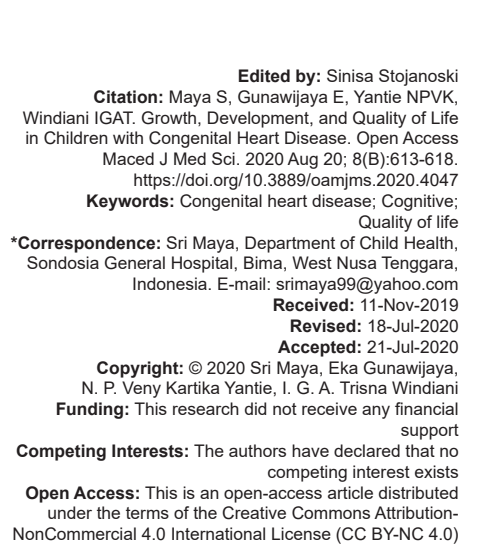

\section{Introduction}

Congenital heart disease (CHD), the most common cause of major congenital anomalies, representing global health problems in pediatric patients [1], [2], [3], [4] with estimated prevalence is 8 per 1000 live births [1]. Despite the advances of medical and surgical care, the increase in survival rates of children with heart disease into adulthood increase [2], several investigators have demonstrated children with $\mathrm{CHD}$ remain at risk for nutritional [1] and cognitive problems [5], [6], [7], [8], [9] which rely on the complexity of the heart lesion. The cognitive disorders include areas of intelligence, academic achievements, languages, visual construction perceptions, attention, executive functioning, fine motor skills, gross motor skills, and psychosocial maladjustment [6], [7]. The impacts of cognitive outcomes for these children vary widely, according to the severity of heart lesions [5] and still being observed many years after successful surgery, manifested as learning or behavioral difficulties, which implies that they are not transient in nature [6].

Despite most of the CHD children have normal birth weight, they tend to develop malnutrition within the first months of life [10], [11]. Decreased energy intake, tissue hypoxia, cardiac acidosis, peripheral acidosis, intestinal malabsorption, increased energy requirement, and attribute infection increase metabolism rate, which ends to growth impairment [1], [3], [10], [12]. Cyanotic heart defect children commonly demonstrate markedly poor growth compared with acynotic defect children [10], [13]. As these children reach adulthood those morbidities can limit educational achievements, employability, insurability, and can particularly affect the child's overall health-related quality of life [7]. As shown by several studies children with cyanotic heart defect have a lower score in quality of life compared with healthy peers in the same age group [14]. In effort to improve the outcome, we aimed to study the nutritional status, cognitive function, and quality of life in children with cyanotic and acyanotic CHD.

\section{Materials and Methods}

This cross-sectional study was conducted from June 2017 to January 2018, Bali, after obtaining clearance from the institutional ethics committees of Udayana university with protocol study number 2017.02.1.0542. 
This study consecutively recruited congenital heart defect children aged 24-69 months old (cyanotic and acyanotic) in Pediatric Cardiology outpatient clinic, with consideration of the instrument we use and cooperation from the child. As we know, 24 months is the starting age to assess the quality of life using PedsQL Cardiac module. Meanwhile, for neurocognitive evaluation using The Mullen Scales of Early Learning (AGS edition) were limited from birth to 69 months old. The required sample size was calculated based on the study by Nasiruzzaman et al. [3] and Rachmawati et al. [4] using power 95\%, alpha 5\% (two-tail), estimated proportion difference $\left(\mathrm{P}_{1}-\mathrm{P}_{2}\right) 40 \%$, and gross motor as the most frequent cognitive problem (which affected $60 \%$ of their sample; 15 from 28 acyanotic; and 15 from 22 acyanotic) [3]; we got 26 children per group from unpaired categorized analytic formula. Meanwhile, the proportion of malnutrition based on the WHO criteria was 19 from in 28 acyanotic [9], with $P_{2} 0.67$, we got 13 subjects per group.

The comparison quality of life from 17 cyanotic children with 37 acyanotic children showed that quality of life-based on parental report was significant lower in cyanotic group in the following segments including heart problem and therapy $(53.3 \pm 9.26$ vs. $71.4 \pm 7.75 ; p=$ $0.007)$, physical appearance (67.5 \pm 20.57 vs. $90.2 \pm$ 4.89; $p=0.033)$, treatment anxiety $(57.3 \pm 11.34$ vs. $83.6 \pm 14.28 ; p=0.001)$, and cognitive problem (53.3 \pm 5.16 vs. $78.3 \pm 4.85 ; p=0.001$ ) [14]. Based on that, the composite of standard deviation using the formula for unpaired analytic categories and numeric we got the biggest sample size was 21 children per group. From the above calculation, we concluded 26 children per group as the biggest sample size for each group.

Children were eligible for inclusion if they presented with symptoms and signs suggestive of CHD, which had been confirmed by echocardiographic examination, parents both mentally and educationally capable of answering the questionnaire and agree to participate by signing the informed consent after been explained the purpose of the study. Patient was excluded from the study if they have clinically genetic syndrome or disorders (Turner, Down, VACTERL association, microcephaly, deafness, blindness), neurologic disorder (cerebral palsy, epilepsy), hematologic or oncology problem (ITP, thalassemia, retinoblastoma, and leukemia), or history of psychiatric problem. Psychiatric problem was assessed if the patient had medical history of being consulted to the psychiatric department or consuming psychiatric medication. Full medical history as well as complete cardiac examination, including the result of echocardiography, catheterization (if one had been done), was documented for all children.

\section{Variables definition}

Cyanotic heart disease was defined as type of $\mathrm{CHD}$ that occurs due to structural defect of the heart (right to left shunting, and malposition of great artery) or any condition which increases pulmonary vascular resistance that causes mixture of oxygenated and unoxygenated blood entering the systemic circulation with oxygen saturation $<85 \%$, for example, tetralogy of Fallot, hipoplastic left heart syndrome, transposition of great artery, tricuspid atresia, pulmonary atresia, and atrioventricular septal defect.

Acyanotic heart disease was defined as type of CHD that occurs due to structural defect of the heart that causes left to right shunting, with normal level of oxyhemoglobin saturation in systemic circulation, for example, ventricular septal defect, atrial septal defect, and patent ductus arteriosus.

Economy class was defined from monthly family income such as money received periodically from commerce, employment, and investments based on Bali Governor decrits no 67/2016 with minimum wages in Denpasar was Rp.2.173.000/month. Anthropometric measurements included weight (kilogram) and height (centimeter) were performed according to standard WHO procedures. Nutritional status was interpreted from Waterlow, the percentage ratio of observed weight, and expected weight from observed height.

In the purpose of assessing child's development status in cognitive and motor ability, we used The Mullen scales of early learning (AGS edition), which consisted of gross motor, visual reception, fine motor, expressive language, and receptive language from birth to 68 months with completion time: $15 \mathrm{~min}$ (1 year); 25-35 min (3 years); and 40-60 min (5 years).

The children's quality of life were assessed using the PedsQL Cardiac module, which was specific to toddlers (2-4 years of age) and young child (5-7 years of age) with heart disease by parents' response. The higher the score, the better the child's quality of life.

Those data, including anthropometric, development, and quality of life, were compared between cyanotic and acyanotic children. Quantitative data were presented in frequency and percentage. The Shapiro-Wilk test was used to analyze the data distribution if $p>0.05$, then its normally distributed and presented as mean and standard deviation (weight in cyanotic, height cyanotic, and acyanotic group). Data with normal distribution were presented as median and percentile, such as age in cyanotic and acyanotic, and weight in acyanotic group. Categorical data including nutritional status, body mass index/age, gross motor, fine motor, receptive language, and early learning composite were analyzed using Chisquare (weight/age z-score [WAZ], and height/age z-score [HAZ]) or Mann-Whitney. Unpaired t-test was used to compare continuous variable with a normal distribution (cognitive problems) and Mann-Whitney for abnormal distributed data (heart problem and therapy, treatment, perceived physical appearance, treatment anxiety, and communication). The significance level was set at $p<0.05$. 


\section{Results}

Demographic and anthropometric characteristics of the samples are shown in Table 1. The median age was 34.0 months for cyanotic $\mathrm{CHD}$ children and 28.5 months for acyanotic CHD children, most of them were dominated by male patients. The majority of patients (both cyanotic and acyanotic) were from middle economic class with monthly income around Rp.2.173.000-6.519.000, and their healthcare were covered by government health insurance. No significant difference in baseline characteristics was seen in both groups.

Table 1: Demographic and anthropometric characteristic

\begin{tabular}{lll}
\hline Demographic characteristic & $\begin{array}{l}\text { Cyanotic CHD } \\
(\mathrm{n}=26)\end{array}$ & $\begin{array}{l}\text { Acyanotic CHD } \\
(\mathrm{n}=26)\end{array}$ \\
\hline $\begin{array}{l}\text { Age, months, median (p10-90) } \\
\text { Gender (males/females) }\end{array}$ & $34 / 24-65.6^{*}$ & $26 / 24-48^{*}$ \\
$\begin{array}{l}\text { Family income, } \mathrm{n}(\%) \\
\quad 12 / 14\end{array}$ & $7 / 19$ \\
$\quad$ & & \\
$\quad$ Lower class & $5(19.2 \%)$ & $3(11.5 \%)$ \\
$\quad \begin{array}{l}\text { Upper class } \\
\text { Anthropometric characteristic, mean (SD) }\end{array}$ & $17(65.3 \%)$ & $22(84.6 \%)$ \\
$\quad$ Weight, kg & $11.75(2.92)^{* *}$ & $1(3.8 \%)$ \\
$\quad$ Height, cm & $89.76(11.98)^{* *}$ & $87.26(9.55)^{* *}$ \\
\hline CHD Congenital heart disease. & &
\end{tabular}

The cyanotic group was dominated by Tetralogy of Fallot; meanwhile, the acyanotic group was dominated by ventricle septal defect, as shown in Table 2.

Table 2: Distribution of heart disease among the patients

\begin{tabular}{ll}
\hline Congenital heart disease & Frequency $\mathrm{n}(\%)$ \\
\hline Acyanotic & \\
PDA & $6(23)$ \\
ASD & $3(11.5)$ \\
VSD & $13(50)$ \\
COA + PDA & $1(3.8)$ \\
PS + ASD-II & $3(11.5)$ \\
Cyanotic & \\
TOF & $13(50)$ \\
TA & $1(3.8)$ \\
DORV & $4(15.4)$ \\
ECD & $3(11.4)$ \\
RV hypoplasia & $1(3.8)$ \\
Pulmonary atresia & $1(3.8)$ \\
PTA & $3(11.5)$ \\
\hline ASD: Atrial septal defect, ECD: Endocardial cushion defect, COA: Coarctation of the aorta, DORV: Double \\
outlet right ventricle, PDA: Patent ductus arteriosus, PS: Pulmonary stenosis, TOF: Tetralogy of Fallot, \\
PTA: Persistent truncus arteriosus, RV: Right ventricle, VSD: Ventricle septal defect, SADC: Sub arterial \\
double committed, TA: Tricuspid atresia, TR: Tricuspid regurgitation, PR: Pulmonary regurgitation.
\end{tabular}

In Table 3, we found a significant difference in proportion of underweight in CHD children $(p=$ 0.008). In cyanotic, the proportion of underweight (WAZ <-2SD) was 43.3\%, which was higher than acyanotic that only $10 \%$. A significant difference was also found in the height/age $(p=0.024)$ in which the cyanotic group showed normal height only in $23.3 \%$, compared with acyanotic, which showed $56.7 \%$. Meanwhile, the proportion of severely stunted was higher in cyanotic (23.3\%) rather than acyanotic $(13.3 \%)$.

The cognitive scores profile of cyanotic and acyanotic CHD children are shown in Table 4. The
Table 3: Comparison of anthropometric profile

\begin{tabular}{llll}
\hline Anthropomrtric variables & Cyanotic CHD (n=26) & Acyanotic CHD (n=26) & $\mathrm{p}$ \\
\hline Nutritional status & ${ }^{+}$ & & \\
Overweight & $3(11.5)$ & $5(19.2)$ & 0.149 \\
Normal & $3(11.5)$ & $7(26.9)$ & \\
Mild malnutrition & $12(46.2)$ & $9(34.6)$ & \\
Moderate malnutrition & $7(26.9)$ & $3(11.5)$ & \\
Severe malnutrition & $1(3.8)$ & $2(7.7)$ & 0.033 \\
WAZ & & & \\
Normal & $8(30.8)$ & $17(65.4)$ & \\
Underweight & $11(42.3)$ & $3(11.5)$ & \\
Severe underweight & $7(26.9)$ & $6(23.1)$ & \\
HAZ & & & \\
Normal & $5(19.2)$ & $13(50.0)$ & \\
Stunted & $11(42.3)$ & $10(38.5)$ & \\
Severe stunted & $10(38.5)$ & $3(11.5)$ & \\
BMl/age ${ }^{+}$ & & & \\
Obese & $3(11.5)$ & $2(7.7)$ & \\
Risky for overweight & $0(0.0)$ & $2(7.7)$ & \\
Normal weight & $17(65.4)$ & $13(50.0)$ & \\
Wasted & $4(15.4)$ & $5(19.2)$ & \\
Severe wasted & $2(7.7)$ & $4(15.4)$ & \\
\hline${ }^{+}$Mann-Whitney, WAZ: Weight for age z-score, HAZ: Height for age z-score, BMI: Body mass index, \\
CHD: Congenital heartdisease.
\end{tabular}

cyanotic CHD children significantly showed lower scored than acyanotic children in gross motor $(p=0.034)$ and in receptive language $(p=0.048)$ which had effect on early learning composite score $(p=0.014)$.

Table 4: Comparison of cognitive function by Mullen

\begin{tabular}{|c|c|c|c|}
\hline Cognitive function & Cyanotic CHD $(\mathrm{n}=26)$ & Acyanotic CHD $(n=26)$ & $p$ \\
\hline \multicolumn{4}{|l|}{ Gross motor $^{+}$} \\
\hline NA & $15(57.7)$ & $9(34.6)$ & \multirow[t]{4}{*}{0.034} \\
\hline Very low & $8(30.8)$ & $8(30.8)$ & \\
\hline Below average & $2(7.7)$ & $2(7.7)$ & \\
\hline Average & $1(3.8)$ & $7(26.9)$ & \\
\hline \multicolumn{4}{|l|}{ Visual reception } \\
\hline Very low & $12(46.2)$ & $10(38.5)$ & \multirow[t]{3}{*}{0.627} \\
\hline Below average & $9(34.6)$ & $8(30.8)$ & \\
\hline Average & $5(19.2)$ & $8(30.8)$ & \\
\hline \multicolumn{4}{|l|}{ Fine motor ${ }^{+}$} \\
\hline Very low & $13(50.0)$ & $14(53.8)$ & \multirow[t]{4}{*}{0.833} \\
\hline Below average & $9(34.6)$ & $5(19.2)$ & \\
\hline Average & $4(15.4)$ & $6(23.1)$ & \\
\hline Very high & $0(0.0)$ & $1(3.8)$ & \\
\hline \multicolumn{4}{|c|}{ Receptive language $^{+}$} \\
\hline Very low & $10(38.5)$ & $6(23.1)$ & \multirow[t]{4}{*}{0.047} \\
\hline Below average & $9(34.6)$ & $4(15.4)$ & \\
\hline Average & $6(23.1)$ & $16(61.5)$ & \\
\hline Above average & $1(3.8)$ & $0(0)$ & \\
\hline \multicolumn{4}{|c|}{ Expressive language } \\
\hline Very low & $13(50.0)$ & $7(26.9)$ & \multirow[t]{3}{*}{0.231} \\
\hline Below average & $6(23.1)$ & $9(34.6)$ & \\
\hline Average & $7(26.9)$ & $10(38.5)$ & \\
\hline \multicolumn{4}{|c|}{ Early learning composite $^{+}$} \\
\hline Very low & $16(61.5)$ & $9(34.6)$ & \multirow[t]{4}{*}{0.044} \\
\hline Below average & $3(11.5)$ & $5(19.2)$ & \\
\hline Average & $7(26.9)$ & $9(34.6)$ & \\
\hline Above average & $0(0.0)$ & $3(11.5)$ & \\
\hline
\end{tabular}

The quality of life assessment from parent's report in cyanotic and acyanotic CHD children is shown in Table 5. In general, the cyanotic children showed lower scores in all the trajectories than children with congenital acyanotic heart disease. Significant differences were found in heart problem and therapy $(p=0.042)$, treatment anxiety $(p=0.016)$, cognitive problems $(p=0.038)$, and communication $(p=0.022)$.

Table 5: Quality of life comparison

\begin{tabular}{llll}
\hline Variables & Cyanotic CHD $(\mathrm{n}=26)$ & $\begin{array}{l}\text { Acyanotic CHD } \\
(\mathrm{n}=26)\end{array}$ & $\mathrm{p}$ \\
\hline Heart problem and therapy & $48.46(17.55)^{* *}$ & $62.49(31.09-92.85)^{*}$ & 0.042 \\
Treatment & $100(25-100)^{*}$ & $100(44.99-100)^{*}$ & 1.000 \\
Perceived physical & $100(89.16-100)^{*}$ & $100(78.32-100)^{*}$ & 0.708 \\
appearance & & & \\
Treatment anxiety & $31.25(25-81.25)^{*}$ & $75(25-100)^{*}$ & 0.016 \\
Cognitive problems & $46.40(21.31)^{* *}$ & $60.76(26.63)^{* *}$ & 0.038 \\
Communication & $75(25-100)^{*}$ & $100(42.5-100)^{*}$ & 0.022 \\
\hline${ }^{*}$ median, p10-90 (data not distributed normally), ${ }^{* *}$ mean, SD (data distributed normally), CHD: Congenital \\
heart disease.
\end{tabular}




\section{Discussion}

Consistent with the previous study on the developmental outcome of children with $\mathrm{CHD}$, our study also found that nutritional problem [3], [10], [15], cognitive delay [3], [5], [9], and lower quality of life [8], [14] are common problems in CHD children [10]. In nutritional assessment, both groups showed the same proportion of severely underweight $50.0 \%$. The cyanotic group was dominated significantly by underweight (WAZ <-2) $42.3 \%$, which differ from the acyanotic group; the proportion of underweight was $15.4 \%$, while it was more dominated by normal weight $(65.4 \%)$. Severe stunted proportion was higher in cyanotic group $38.5 \%$ compared with acyanotic only $11.5 \%$. Most of the acyanotic group was found had normal height $(50 \%)$ based on $\mathrm{HAZ}$, in comparison to cyanotic group, which was dominated by stunted children (42.3\%). Cyanotic patients were affected in growth, depending on the severity of tissue hypoxemia and the degree of physiological adaptation. Acyanotic lesions, affect weight more than height. In other words, cyanotic lesions were related to chronic malnutrition, whereas acyanotic lesions were related to acute malnutrition [15].

Our study is in accordance with study in India, which showed the majority of the CHD children were malnourished, and weight was found to be more affected than height in both cyanotic and acyanotic groups. Both height and weight were affected much more in the cyanotic group when compared to acyanotic group, despite not significant statistically by height category [12]. It also appropriates with a study in Cairo which found that malnutrition, stunting, and wasting proportion were significantly higher among cyanotics $(62.8 \%, 74.4 \%$, and $25.6 \%)$ compared with acyanotics $(49.5 \%, 63.3 \%$, and $18.3 \%)$ [12]. In addition, cyanotic heart defect was known to have a correlation with the decrement of insulin growth factor-1 level $(r=0.402, p<0.05)$ [14], which is in agreement with Eren et al. who stated chronic hypoxia had a negative effect on nutrition and growth hormone, by decreasing insulin growth factor-1 (somatomedin) level that is produced in the liver and regulated by the binding of growth hormone to growth hormone receptors. These findings indicated that chronic hypoxemia might serve as the underlying cause by decreasing the production of insulin growth factor-1 which induced growth failure in patients with cyanotic CHD [11], [16], [17].

Normal fetal brain growth and development rely on adequate delivery of oxygen and substrate, which is influenced by the anatomic structure of the heart and myocardial function [9]. CHD fetal has delayed brain growth since the third trimester, characterized by a decrement of $\mathrm{N}$-acetylaspartate/Choline ratio (Naa/Cho) and Choline/Creatinine ratio (Cho/Cr), and increment of Myoinositol/Choline (Ino/Cho) and lactate [18]. Thus underlies the worse neurocognitive outcomes
[9] in children with cyanotic heart defects due to less mature macro and micro structural brain development with lower total brain volume as proven by Rollins et al., that CHD children have reduction of total brain volume at 1 year of age driven by differences in cerebral white matter which correlates with language impairment [18]. In our study, receptive language impairment was more significant in cyanotic group compared with acyanotic, which can be caused by the reduction of total brain volume $(p=0.047)$.

In addition, the prolonged period of hypoxics cerebral vascular tone in CHD tends to normalize, with downregulation of neuronal and glial metabolism that results in reduced cerebral VO2 leads to periventricular leukomalacia, characterized by focal necrosis in the periventricular white matter [19], [20], [21]. Those alterations of white matter will disturb volumetric growth, gyrification of the cortical gray matter, and impair myelination which linked to worse cognition, motor and behavioral functioning, as well [22], [23].

Recently, a systematic review stated that brain metabolism and microstructural development also played role in delayed cerebral development, which was significantly lower than neonates without congenital heart defect and corresponded to a delay of 4 weeks in structural brain sulcation [23]s.

Our study showed the proportion of underweight was significantly higher in cyanotic group, which would increase morbidity and mortality, as indicated by frequent hospitalization, poor surgical outcomes, persistent impairment of somatic growth, and increased death. The underweight can be caused by feeding problems such as inadequate nutritional intake or absorption, feeding difficulty, excessive energy expenditure, frequent respiratory infections, limitation of growth potential, and genetic syndromes [15]. The feeding difficulty in CHD infants can be linked to oropharyngeal dysphagia [24]. Moreover, these feeding and language problems also can be linked to the immaturity of brain development proven by the incomplete closure of the cerebral opercula, which is the sensory-motor cortical representation of buccal, glottis, and esophageal structures, as well as receptive and expressive language [20].

Besides nutrition, in cognitive trajectory evaluated by Mullen showed that cyanotic group had significant impairment in gross motor and receptive language than acyanotic group. It showed agreement with a study in Bangladesh in which about $32 \%$ had cognitive impairment, $44 \%$ children had speech delay, with gross motor and fine motor delay as the main developmental problems [25]. Besides brain impairment, the development of motor skills in children (infants until school-age) also takes place as a resultant of activity and interaction between person and environment. Children influence their environment in an active way and adapt their behavior to the environment. Movement serves as a catalyst 
in a child's development. In this way, high level of movement ensures the advancement of the child's physical development, especially the locomotor system, which, through movement, gains the impulses needed for normal development [26]. Interestingly, we also found parents focused on the treatment and tend to restrict their child physical activity. We assumed it was caused by lack of adequate information to caregiver or parents, who limit the child's motoric stimulation that possibly causes development delay by restriction of physical activity and sheltered upbringing by main caregivers, who are generally more protective. Majority of parents who have children with CHD were reported to have a higher stress level compared with the normal population that makes them difficult to set limit and control for their children. They tend to assimilate their parenting style in accordance with the child's need that leads to overprotective behavior. Finally, it will limit the children interaction with their peers, not least regarding physical activity, which might influence the child's social competence and motor development [26].

Despite the measures taken to treat, these children may experience maladjustment in physical activities, social relationships, academic performances, and emotional, which decrease the quality of life in CHD patients. The quality of life assessment from parent's reports in cyanotic significantly lower than acyanotic in the following aspect such as heart problems and therapy, treatment anxiety, cognitive problems, and communication. In our study, the cyanotic showed the poor quality of life than acyanotic heart disease children; it supposed to be related to the difference in cognitive and nutritional status. Therefore, a multidisciplinary approach should be applied for early identification of those impairments to offer the best opportunity for treatment that may allow the child to reach the fullest potential in adulthood and minimize the negative impact on the quality of life and parents should be more aware and responsive to the development and nutrition aspect of their child [27].

\section{Conclusion}

Cognitive delay, nutritional problems, and quality of life are common in cyanotic CHD children.

\section{Acknowledgments}

All nurses, residents, children with $\mathrm{CHDs}$, and their parents for their willingness to participate in this study.

\section{References}

1. Ulfah DA, Lestari ED, Harsono S. The effect of cyanotic and acyanotic congenital heart disease on children's growth velocity. Paediatr Indones. 2017;57(3):159-62. https://doi.org/10.14238/ pi57.3.2017.160-3

2. Van der Linde $D$, Konings $E E$, Slager MA, Witsenburg $M$, Helbing WA, et al. Birth prevalence of congenital heart disease worldwide a systematic review and meta-analysis. J Am Coll Cardiol. 2011;58(21):2241-7. https://doi.org/10.1016/j. jacc.2011.08.025

PMid:22078432

3. Nasiruzzaman AH, Hussain MZ, Baki MA, Tayeb MA, Mollah MN Growth and developmental status of children with congenital heart disease. Bangladesh Med J. 201/;4(2):54-8. https://doi. org/10.3329/bmj.v40i2.18512

4. Karthiga S, Pathak S, Lazarus M. Clinical and anthropometric profile of congenital heart disease in children admitted in pediatric. Int J Sci Stud. 2017;5(5):112-7.

5. Mussatto KA, Hoffmann RG, Hoffman GM, Tweddell JS, Bear L, Cao $\mathrm{Y}$, et al. Risk and prevalence of developmental delay in young children with congenital heart disease. Pediatrics. 2014;133(3):e570-7. https://doi.org/10.1542/peds.2013-2309 PMid:24488746

6. Bryn J, Frank M, Owen L, Lynne M, Robert J. Neurodevelopmenta outcome following open heart surgery in infancy: 6-year follow-up. Cardiol Young. 2015;25(5):903-10. https://doi. org/10.1017/s1047951114001140

PMid:25008002

7. Marelli A, Miller SP, Marino BS, Jefferson AL, Newburger JW. Brain in congenital heart disease across the lifespan: The cumulative burden of injury. Circulation. 2016;133(20):1951-62. https://doi.org/10.1161/circulationaha.115.019881

PMid:27185022

8. Mussatto KA, Hoffmann R, Hoffman G, Tweddell JS, Bear L, Cao $\mathrm{Y}$, et al. Risk factors for abnormal developmental trajectories in young children with congenital heart disease. Circulation. 2016;132(8):755-61. https://doi.org/10.1161/ circulationaha.114.014521

PMid:26304667

9. Khalil A, Suff N, Thilaganathan B, Hurrell A, Cooper D, Carvalho JS. Brain abnormalities and neurodevelopmental delay in congenital heart disease: Systemic review and metaanalysis. Ultrasound Obstet Gynecol. 2014;43(1):14-24. https:// doi.org/10.1002/uog.12526 PMid:23737029

10. Blasquez A, Clouzeau H, Fayon M, Mouton JB, Thambo JB, Enaud R, Lamireau T. Evaluation of nutritional status and support in children with congenital heart disease. Eur J Clin Nutr. 2016;70(4):528-31. https://doi.org/10.1038/ejcn.2015.209 PMid:26695725

11. Eren E, Cakir ED, Bostan O, Saglam H, Tarim O. Evaluation of endocrine functions in pediatric patients with cyantic congenital heart disease. Biomed Res. 2013;24(1):77-81.

12. Habeeb NM, Al-Fahham MM, Tawfik AA, Mohammed MM Nutritional assessment of children with congenital heart disease a comparative study in relation to type, operative intervention and complications. EC Pediatr. 2017;6(4):112-20.

13. Okoshi MP, Capalbo RV, Romeiro FG, Okoshi K. Cardiac cachexia: Perspectives for prevention and treatment. Arq Bras Cardiol. 2017;108(1):74-80. https://doi.org/10.5935/ abc. 20160142

PMid:27812676

14. Rachmawati CF, Sri S, Muhammad A. Assessment of quality 
of life in children with congenital heart disease of asianosis and cyanosis. Sari Pediatri. 2014;16(2):86-90. https://doi. org/10.14238/sp16.2.2014.86-90

15. Sjarif DR, Anggriawan SL, Putra ST, Djer MM. Anthropometric profiles of children with congenital heart disease. Med J Indones. 2011;20(1):40-5. https://doi.org/10.13181/mji.v20i1.426

16. Dündar BN, Saylam GS, Akçoral A, Atilla B. Chronic hypoxemia leads to reduced serum IGF-I levels in cyanotic congenital heart disease. J Pediatr Endocrinol Metab. 2000;13(4):431-6. https:// doi.org/10.1515/jpem.2000.13.4.431

PMid:10776998

17. Elwan SA, Assar EH, Essa EA, Elsaid DA. Assessment of serum insulin-like growth factor 1 and serum insulin in children with congenital heart disease. Benha Med J. 2015;32(1):36-40. https://doi.org/10.4103/1110-208x.170557

18. Rollins CK, Asaro LA, Akhondi-Asl A, Kussman BD, Rivkin MJ, Bellinger DC, et al. White matter volume predicts language development in congenital heart disease. J Pediatr. 2017;181:428. https://doi.org/10.1016/j.jpeds.2016.09.070 PMid:27837950

19. Sun L, Macgowan CK, Sled JG, Yoo SJ, Manlhiot C, Porayette P, et al. Reduced fetal cerebral oxygen consumption is associated with smaller brain size in fetuses with congenital heart disease. Circulation. 2015;131(15):1313-23. https://doi.org/10.1161/ circulationaha.114.013051 PMid:25762062

20. Licht DJ, Shera DM, Clancy RR, Wernovsky G, Montenegro LM, Nicolson SC, et al. Brain maturation is delayed in infants with complex congenital. J Thoracic Cardiovasc Surg. 2009;137(3):529-37. https://doi.org/10.1016/j.jtcvs.2008.10.025 PMid:25762062

21. Varsha J, Buckley EM, Licht DJ, Lynch JM, Schwab PJ, Naim MY. Cerebral oxygen metabolism in neonates with congenital heart disease quantified by MRI and optics. J Cereb
Blood Flow Metab. 2014;34(3):380-8. https://doi.org/10.1038/ jcbfm.2013.214

PMid:24326385

22. Claessens NH, Moeskops P, Buchmann A, Latal B, Knirsch W, Scheer I, et al. Delayed cortical gray matter development in neonates with severe congenital heart disease. Pediatr Res. 2016;80(5):668-74. https://doi.org/10.1038/pr.2016.145

PMid:27434120

23. Mebius MJ, Kooi EM, Bilardo CM, Bos AF. Brain injury and neurodevelopmental in congenital heart disease: A systematic review. Pediatrics. 2017;140(1):e20164055. https://doi. org/10.1542/peds.2016-4055

PMid:28607205

24. Pereira KD, Firpo C, Gasparin M, Teixeira AR, Dornelles S, Bacaltchuk $\mathrm{T}$, et al. Evaluation of swallowing in infants with congenital heart defect. Int Arch Otorhinolaryngol. 2015;19(1):55-60. https://doi.org/10.1055/s-0034-1384687 PMid:25992152

25. Calarge C, Farmer C, DiSilvestro R, Eugene A. Serum ferritin and amphetamine response in youth with attention deficit/ hyperactivity disorder. J Child Adolesc Psychopharmacol. 2010;20(6):495-502. https://doi.org/10.1089/cap.2010.0053 PMid:21186968

26. Wehrens B, Schmitz S, Dordel S, Schickendantz S, Krumm C, Bott D, et al. Motor development in children with congenital cardiac diseases compared to their healthy peers. Cardiol Young. 2007;17(5):487-98. https://doi.org/10.1017/ s1047951107001023

PMid: 17666153

27. Mari MA, Cascudo MM, Alchieri JC. Congenital heart disease and impacts on child development. Braz J Cardiovasc Surg. 2016;31(1):31-7. https://doi.org/10.5935/1678-9741.20160001 PMid:27074272 